Jurnal Politico Vol. 2 September 2018

Halaman 206-218. ISSN: p; 1829-6696, e:2549-4716

Web jurnal online; jurnal.unmuhjember.ac.id

Emy Kholifah, R., Nor Eviatul Sadiah

PENGARUH INTERAKSI PEMERINTAH, BURUH DAN PELAKU USAHA TERHADAP

PENETAPAN UPAH MINIMUM KABUPATEN

(STUDY KASUS DI KABUPATEN JEMBER)

\title{
PENGARUH INTERAKSI PEMERINTAH, BURUH DAN PELAKU USAHA TERHADAP PENETAPAN UPAH MINIMUM KABUPATEN (STUDY KASUS DI KABUPATEN JEMBER)
}

\author{
Oleh : \\ Emy Kholifah, R., Nor Eviatul Sadiah \\ Program Studi Ilmu Pemerintahan \\ Fakultas Ilmu Sosial dan Ilmu Politik Universitas Muhammadiyah Jember \\ Received: 15 Agustus 2018,Revised: 25 Agustus 2018, Accepted: 26 Agustus 2018 \\ Email: emykholifah25@gmail.com
}

\begin{abstract}
ABSTRAK
Interaksi adalah salah satu syarat untuk terjadinya aktivitas antara individu yang satu dengan individu yang lain individu dengan kelompok, dan kelompok dengan kelompok. Upah adalah penghargaan atas hasil kerja pekerja suatu perusahaan tempat mereka bekerja. Dalam hal pengupahan perlu adanya suatu aturan yang jelas dan proses yang jelas sebelum upah itu ditetapkan. Dengan adanya uraian tersebut maka penulis ingin meneliti proses yang terjadi sebelum upah tersebut di tetapkan dengan judul: Pengaruh Interaksi Pemerintah, Buruh dan Pelaku Usaha Terhadap penetapan Upah Minimum Kabupaten di Kabupaten Jember. Penelitian ini bertujuan antara lain: mengetahui bagaimana pengaruh interaksi pemerintah, buruh dan pelaku usaha terhadap penetapan Upah Minimum Kabupaten. Teori yang dipergunakan adalah teori interaksi sosial, jenis penelitian menggunakan metode deskriptif kuantitatif dengan lokasi penelitian Dinas Ketenagakerjaan Kabupaten Jember, pengumpulan data menggunakan metode kuisoner dan wawancara. Dari hasil penelitian menunjukan bahwa: adanya pengaruh interaksi pemerintah, buruh dan pelaku usaha pada penetapan upah minimum kabupaten sehingga pada proses penetapan upah minimum kabupaten terjalin kejasama atau interaksi yang baik antara tiga unsur tersebut. Sehingga penetapan upah minimum kabupaten berjalan dengan baik setiap tahunya meskipun ada masalah - masalah yang timbul. Akan tetapi pemerintah mampu menyelesaikan masalah yang timbul sehingga setiap tahunnya dapan menetapkan upah minimum kabupaten.

Kata Kunci: Interaksi Pemerintah, Buruh dan Pelaku Usaha, Penetapan Upah Minimum Kabupaten
\end{abstract}


Jurnal Politico Vol. 2 September 2018

Halaman 206-218. ISSN: p; 1829-6696, e:2549-4716

Web jurnal online; jurnal.unmuhjember.ac.id

Emy Kholifah, R., Nor Eviatul Sadiah

PENGARUH INTERAKSI PEMERINTAH, BURUH DAN PELAKU USAHA TERHADAP

PENETAPAN UPAH MINIMUM KABUPATEN

(STUDY KASUS DI KABUPATEN JEMBER)

\begin{abstract}
Interaction is one of the requirements for the occurrence of activities - anatara activities inidividu one with other individuals or individuals with the group. Wages are a reward for the work that workers do for a company where they work. In the case of wages there needs to be a clear rule and a clear process before the wages are fixed. With the description, the authors want to examine more deeply about the process that occurred before the wage is set and pour it further in the form of a thesis entitled: Influence Interaction Government, Labor and Business Actors to the determination of District Minimum Wage in Jember District. This study aims are: To know how the influence of government interaction, laborers and business actors to the determination of District Minimum Wage. The theory used is the theory of social interaction, the type of research using quantitative descriptive method with the location of research Department of Manpower Jember district, data collection using questionnaire and interview methods. From the research result show that: the influence of interaction of government, laborer and business actor in determination of minimum wage determination of kabuptaen so that in process of determination of minimum wage of district is established cooperation or good interaction between three element. So the determination of the district minimum wage goes well every year despite the problems that arise. However, the government is able to resolve the problems that arise so that each year it can set the district minimum wage.
\end{abstract}

Keywords: Government Interaction, Labor and Business Actors, Determination of Regency Minimum Wage 
Jurnal Politico Vol. 2 September 2018

Halaman 206-218. ISSN: p; 1829-6696, e:2549-4716

Web jurnal online; jurnal.unmuhjember.ac.id

Emy Kholifah, R., Nor Eviatul Sadiah

PENGARUH INTERAKSI PEMERINTAH, BURUH DAN PELAKU USAHA TERHADAP

PENETAPAN UPAH MINIMUM KABUPATEN

(STUDY KASUS DI KABUPATEN JEMBER)

\section{PENDAHULUAN}

Dalam dunia industri buruh adalah modal atau faktor penting dalam suatu proses produksi. Buruh juga sebagai salah satu faktor yang dapat berpengaruh pada keberhasilan dalam menciptakan produk atau barang. Oleh karena itu setiap buruh atau para pekerja industri perlu mendapat perhatian dari pemerintah pusat maupun daerah agar mendapat haknya dalam melakukan pekerjaan. Pemerintah juga memiliki tanggung jawab dalam mengatur dan melindungi para buruh serta pelaku industri atau perusahaan yang ada di Kabupaten Jember.

Keterlibatan pemeintah daerah dalam mengatur serta memberikan pengawasan terhadap kegiatan industri di suatu daerah dapat memberikan dampak yang besar dalam kegiatan di dalam suatu industri tersebut. Para pelaku industri harus memberikan kewajiban - kewajibannya kepada para buruh serta memberikan fasilitas yang baik agar para buruh yang berkerja merasa disejahterakan oleh perusahaan tersebut. Jika antar buruh dan pelaku industri memiliki hubungan serta kerjasama yang baik maka tidak akan timbul masalah atau problem dalam suatu hubungan kerja.

Dalam hal ini pemerintah setiap tahunnya menentukan UMR (Upah Minimum Regional). Berdasarkan Peraturan Mentri Tenaga Kerja Nomor PER01/MEN/1999 Tentang "Upah Minimum", Upah Minimum Regional dibagi menjadi dua yang pertama UMR Tk.I merupakan upah minimum regional yang berlaku di satu provinsi dan UMR Tk.II merupakan upah minimum yang berlaku di Kabupaten / Kota.

Apabila stabilitas ekonomi mengalami guncangan, secara tidak langsung akan terjadi dampak bagi perusahaan berupa tekanan dalam bentuk naiknya biaya produksi serta distribusi. Biaya produksi akan meningkat bila tingkat upah yang ditetapkan naik. Agar terjadi efisiensi perusahaan, dilakukan pengurangan pegawai yang mengakibatkan pada menurunnya tingkat kesempatan kerja. Hal ini 
Jurnal Politico Vol. 2 September 2018

Halaman 206-218. ISSN: p; 1829-6696, e:2549-4716

Web jurnal online; jurnal.unmuhjember.ac.id

Emy Kholifah, R., Nor Eviatul Sadiah

PENGARUH INTERAKSI PEMERINTAH, BURUH DAN PELAKU USAHA TERHADAP

PENETAPAN UPAH MINIMUM KABUPATEN

(STUDY KASUS DI KABUPATEN JEMBER)

akan berdampak negatif terhadap pengangguran. Penetapan upah minimum diatas harga keseimbangan pasar dapat menyebabkan meningkatnya jumlah pengangguran. Bila upah naik, akan terjadi penurunan jumlah tenaga kerja yang dibutuhkan. Hal tersebut akibat dari meningkatnya jumlah pencari kerja yang menginginkan memperoleh pekerjaan pada level upah tinggi namun tidak sesuai dengan sedikitnya/minimnya jumlah tenaga kerja yang diminta oleh perusahaan.

\section{TINJAUAN PUSTAKA}

\section{Interaksi Sosial}

Interaksi sosial merupakan bentuk umum dari proses sosial. Interaksi sosial menjadi syarat utama aktivitas sosial terbentuk. Interaksi sosial adalah hubungan sosial dinamis menyangkut hubungan antara orang-perorangan, antar kelompok manusia, maupun antar orang perorangan dengan kelompok manusia serta antara kelompok dengan kelompok. Jika dua orang bertemu, berinteraksi sosial saat itu. asaling bertegur sapa, berjabat tangan, saling berkomunikasi serta berkelahi. Aktivitas tersebut adalah bentuk interaksi sosial. Walaupun orang bertemu muka tidak saling bicara hal tersebut menimbulkan kesan didalam pikiran seseorang, selanjutnya menyebabkan tindakan apa yang akan diambil sebagai reaksi.

\section{Upah Minimum}

Upah minimum adalah suatu penerimaan/pendapatan/penghasilan bulanan minimum (terendah) yang merupakan imbalan dari perusahaan pengusaha kepada pegawai/karyawan atas pekerjaan dan jasa yang telah atau akan dilakukan serta dinyatakan dan dinilai dalam bentuk uang ditetapkan berdasar atas suatu persetujuan atau peraturan perundang - undangan serta dibayarkan atas dasar suatu kesepakatan dan perjanjian kerja antara perusahaan/pengusaha dengan pegawai/karyawan serta tunjangan karyawan dan keluarganya. Peraturan Menteri 
Jurnal Politico Vol. 2 September 2018

Halaman 206-218. ISSN: p; 1829-6696, e:2549-4716

Web jurnal online; jurnal.unmuhjember.ac.id

Emy Kholifah, R., Nor Eviatul Sadiah

PENGARUH INTERAKSI PEMERINTAH, BURUH DAN PELAKU USAHA TERHADAP

PENETAPAN UPAH MINIMUM KABUPATEN

(STUDY KASUS DI KABUPATEN JEMBER)

Tenaga Kerja Nomor Per-01/MEN/1999 tentang Upah Minimum Bab I Pengertian Pasal 1 ayat (1), yaitu dimaksud dengan "Upah Minimum adalah upah bulanan terendah yang terdiri dari upah pokok termasuk tunjangan tetap". Ayat (2): "Upah Minimum Tingkat 1 untuk selanjutnya disebut UMR Tk 1 adalah Upah Minimum yang berlaku di satu Propinsi”. Ayat (3) : “Upah Minimum Regional Tingkat II untuk selanjutnya disebut UMR Tk II adalah Upah Minimum yang berlaku di daerah Kabupaten/Kota atau menurut wilayah pembangunan ekonomi daerah atau karena kehususannya wilayah tertentu".

\section{Pekerja atau Pelaku Usaha}

Menurut Karl Marx pelaku utama perubahan sosial bukanlah individu tertentu, tetapi adalah kelas sosial. Kita dapat memaknai sejarah dengan perkembangan dinamis jika kita mengamati kelas sosial dalam masyrakat. Tidak hanya kelas macam apa yang ada, melainkan bagaimana struktur kekuasaan. Menurut Marx, akan terlihat bahwa dalam setiap masyarakat dapat ditemui kelas yang berkuasa dan yang dikuasai oleh kelompok tertentu. Marx menjelaskan kelas atas dan kelas bawah dan fokus pada masyarakat kontemporer.

\section{Lembaga Kerja Sama Tripartit}

Sistem tripartisme merujuk pada korporatisme atau kerja sama ekonomi berdasar atas kontrak tiga pihak yaitu afiliansi bisnis, buruh, serta negara di bidang ekonomi masing - masing efisiensi sebagai mitra sosial dalam rangka mewujudkan kebijakan ekonomi dengan mengadakan kerjasama, konsultasi, negosiasi serta kompromi. Dalam dunia Ketenagakerjaan merupakan wujud hubungan antara pemerintah, pengusaha dan pekerja/buruh sedangkan tripartisme dalam bentuk kelembagaan di Indonesia, salah satunya adalah Lembaga Kerjasama Tripartit (LKS Tripartit). Lembaga Kerjasama Tripartit ini terdiri dari 
Jurnal Politico Vol. 2 September 2018

Halaman 206-218. ISSN: p; 1829-6696, e:2549-4716

Web jurnal online; jurnal.unmuhjember.ac.id

Emy Kholifah, R., Nor Eviatul Sadiah

PENGARUH INTERAKSI PEMERINTAH, BURUH DAN PELAKU USAHA TERHADAP

PENETAPAN UPAH MINIMUM KABUPATEN

(STUDY KASUS DI KABUPATEN JEMBER)

Lembaga Kerjasama Tripartit Nasional, Propinsi dan Kabupaten/Kota dan Lembaga Kerjasama Tripartit Nasional, Propinsi dan Kabupaten/Kota.

\section{Dewan Pengupahan Daerah}

Dewan pengupahan daerah merupakan suatu lembaga non struktural yang bersifat Tripartit. Berdasarkan Keppres 107 Tahun 2004, terbagi atas Dewan Pengupahan Nasional, Dewan Pengupahan Provinsi dan Dewan Pengupahan Kabupaten/Kota. Secara yuridis, Dewan Pengupahan diatur di dalam Keputusan Presiden No. 107 tentang Dewan Pengupahan yang memiliki kewenangan masing-masing.

\section{Mekanisme Penetapan Upah Minimum Kabupaten}

Dewan Pengupahan Kabupaten menyampaikan hasil rumusan kepada Bupati sehingga Bupati akan menimbang dari segi pekerja, pengusaha, pertumbuhan ekonomi. Rumusan oleh Dewan Pengupah Kabupaten yang dikonsultasikan kepada pemerintah selanjutnya Bupati megambil kebijakan stategis dalam pengambilan keputusan sebagai rekomendasi Gubernur. Rekomendasi tersebut oleh Gubernur dikaji ulang berdasar saran dari Dewan Pengupahan Provinsi. Selain upah minimum, Gubernur dapat pula menetapkan Upah Sektoral Provinsi (UMS Provinsi) berdasar atas kesepakatan upah antara pengusaha/perusahaan dengan serikat pekerja/pegawai atau serikat buruh.

\section{METODOLOGI PENELITIAN}

\section{Jenis Penelitian}

Penelitian ini merupakan penelitian menggunakan pendekatan kuantitatif deskriptif asosiatif. Pengukuran, perhitungan, rumus dan kepastian data numerik dilakukan di dalam usulan penelitian, proses, hipotesis, turun kelapangan, analisis 
Jurnal Politico Vol. 2 September 2018

Halaman 206-218. ISSN: p; 1829-6696, e:2549-4716

Web jurnal online; jurnal.unmuhjember.ac.id

Emy Kholifah, R., Nor Eviatul Sadiah

PENGARUH INTERAKSI PEMERINTAH, BURUH DAN PELAKU USAHA TERHADAP

PENETAPAN UPAH MINIMUM KABUPATEN

(STUDY KASUS DI KABUPATEN JEMBER)

data dan kesimpulan data sampai dengan penulisannya. Fakta - fakta dan sifat sifat suatu populasi atau daerah tertentu secara sistematik, faktual dan teliti dideskripsikan (Ginting, 2008:55).

\section{Lokasi Penelitian}

Lokasi diperlukan dalam suatu penelitian untuk membatasi wilayah penelitian. Lokasi penelitian menurut Bungin (dalam Yuswadi 2007:120) merupakan tempat dimana penelitian dan kegiatan penelitian memperoleh data data yang diperlukan dan menjawab pertanyaan - pertanyaan yang telah ditetapkan. Penelitian ini dilakukan di Dinas Ketenagakerjaan Kabupaten Jember dengan alasan penelitian memilih disini karena mudah dijangkau.

\section{Populasi Penelitian}

Populasi merupakan keseluruhan dari objek yang karakteristiknya hendak diduga (Arikunto, 2006:130). Bahwa populasi adalah keseluruhan dari unit analisis yang ciri - cirinya akan diduga (Singarimbun 2005:6). Populasi dalam penelitian ini adalah perwakilan buruh/pegawai/pekerja serta perwakilan pelaku usaha yang tergabung dalam tripartit di Kabupaten Jember.

\section{Sampel Penelitian}

Sampel adalah sebagian atau wakil dari jumlah populasi yang diteliti (Arikunto 206:131). Sampel penelitian ini adalah satu perwakilan pekerja, satu perwakilan pengusaha dan satu perwakilan dari pemerintah yang ada di Kabupaten Jember. 
Jurnal Politico Vol. 2 September 2018

Halaman 206-218. ISSN: p; 1829-6696, e:2549-4716

Web jurnal online; jurnal.unmuhjember.ac.id

Emy Kholifah, R., Nor Eviatul Sadiah

PENGARUH INTERAKSI PEMERINTAH, BURUH DAN PELAKU USAHA TERHADAP

PENETAPAN UPAH MINIMUM KABUPATEN

(STUDY KASUS DI KABUPATEN JEMBER)

\section{HASIL DAN PEMBAHASAN}

\section{Kerjasama Dalam Proses Penetapan Upah Minimum Kabupaten Jember}

Atas pembahasan pada kerjasama dalam proses penetapan UMK terkait lima aspek yaitu aspek kerukunan, aspek bargaining, aspek kooptasi, aspek koalisi, dan aspek joint ventrue yang berupa pernyatan - pernyatan tentang interaksi yang terjadi. Interaksi tersebut yang menyangkut kepentingan antara pekerja dan pelaku usaha atau kepentingan bersama para narasumber atau responden memberikan jawaban sesuai fakta/kenyataan di lapangan. Serta menjelaskan dan memberikan jawaban bahwa kerjasama yang terjadi dalam proses penetapan UMK dilakukan dengan baik oleh pemerintah, pekerja dan pelaku usaha dalam menetapkan UMK.

\section{Akomodasi Dalam Proses Penetapan Upah Minimum Kabupaten}

Pembahasan akomodasi pada saat proses penetapan UMK yang terdiri dari tuju aspek antara lain aspek coercion, aspek compromise, aspek arbitration, aspek mediation, aspek conciliation, aspek toleration dan aspek stalemate. Yang berupa pernyataan serta wawancara para pesponden dan narasumber menjelaskan pada proses ini interaksi berjalan dengan baik antara pekerja, pelaku usaha dan pemerintah. Hal ini terjadi karena antar ketiga pihak saling bekerjasama dalam melakukan proses yang harus dilakukan sebelum penetapan UMK. Pemerintah selaku penengah juga mampu menjadi fasilitator bagi dua kelompok yaitu kelompok pekerja dan kelompok pengusaha. Sehingga pada saat proses penetapan UMK segala permasalahan mampu di selesaikan.

\section{Proses Penetapan UMK}

Pada proses penetapan UMK, pemerintah, pelaku usaha dan pekerja melakukan tahapan atau proses penetapan UMK di kabupaten Jember sudah sesuai dengan alur yang sudah ada dan ditetapkan. Pekerja, pelaku usaha dan pemerintah sudah mampu menjalankan prosedur - prosedur sebelum 
Jurnal Politico Vol. 2 September 2018

Halaman 206-218. ISSN: p; 1829-6696, e:2549-4716

Web jurnal online; jurnal.unmuhjember.ac.id

Emy Kholifah, R., Nor Eviatul Sadiah

PENGARUH INTERAKSI PEMERINTAH, BURUH DAN PELAKU USAHA TERHADAP

PENETAPAN UPAH MINIMUM KABUPATEN

(STUDY KASUS DI KABUPATEN JEMBER)

ditetapkannya UMK di Kabupaten Jember. Sehingga UMK yang ada dapat diterima dengan baik oleh pekerja dan pelaku usaha di Kabupaten Jember.

\section{Pengaruh Interaksi Pemerintah, Buruh dan Pelaku Usaha Terhadap Penetapan Upah Minimum Kabupaten}

Dalam proses penetapan upah kabupaten pemerintah melibatkan tiga unsur yang terkait dalam pengupahan. Tiga unsur ini terdiri dari pekerja, pelaku usaha dan pemerintah yang tergabung dalam satu organisasi yang disebut Dewan Pengupahan Daerah. Disini mereka memiliki tujuan yang sama yakni tujuan dari mereka adalah menetapkan upah kabuten. Mereka yang tergabung dalam Dewan Pengupahan Daerah merupakan pewakilan dari tiga unsur tersebut. Dalam proses berlangsungnya penetapan Upah Minimum Kabupaten terjadi interaksi antar ketiga unsur tersebut. Interaksi yang berlangsung dapat mempermudah mereka dalam proses penetapan Upah Minimum Kabupaten, salah satu interaksi yang terjadi pada saat rapat mereka berbicara atau memberikan pendapatnya. Dalam hal ini saya akan menjelaskan pengaruh interaksi antar ketiga unsur sebagai berikut:

a. Correlation Kerjasama dengan Proses Penetapan UMK

\begin{tabular}{|c|r|c|}
\hline & kerjasama & $\begin{array}{c}\text { proses penetapan } \\
\text { UMK }\end{array}$ \\
\hline kerjasama & 1 & \\
\hline $\begin{array}{c}\text { Proses } \\
\text { penetapan } \\
\text { UMK }\end{array}$ & 0,634546714 & \\
\hline
\end{tabular}

Correlatioan antara kerjasama dengan proses penetapan UMK mendapatkan hasil angka 0,634546714 yang menjelaskan bahwa hubungan correlation pada proses penetapan UMK di Kabupaten Jember memiliki hubungan 
Jurnal Politico Vol. 2 September 2018

Halaman 206-218. ISSN: p; 1829-6696, e:2549-4716

Web jurnal online; jurnal.unmuhjember.ac.id

Emy Kholifah, R., Nor Eviatul Sadiah

PENGARUH INTERAKSI PEMERINTAH, BURUH DAN PELAKU USAHA TERHADAP

PENETAPAN UPAH MINIMUM KABUPATEN

(STUDY KASUS DI KABUPATEN JEMBER)

yang correlation yang kuat jadi kerjasama antara pekerja, pelaku usaha dan pemerintah memberikan pengaruh untuk proses penetapan UMK.

b. Correlation Akomodasi dengan Proses Penetapan UMK

\begin{tabular}{|c|c|c|}
\hline & akomodasi & $\begin{array}{c}\text { proses penetapan } \\
\text { UMK }\end{array}$ \\
\hline akomodasi & 1 & \\
\hline $\begin{array}{c}\text { proses } \\
\text { penetapan UMK }\end{array}$ & 0,72581371 & 1 \\
\hline
\end{tabular}

Correlation antara akomodasi dan proses penetapan UMK mendapat hasil angka 0,72581371 yang menjelaskan bahwa hubungan correlation pada proses penetapan UMK di Kabupaten Jember memiliki hubungan correlation yang kuat. Jadi akomodasi pada proses penetapan UMK terjadi pada penetapan UMK di Kabupaten Jember memiliki pengaruh.

c. Correlation Bentuk Interaksi dengan Proses Penetapan UMK

\begin{tabular}{|c|r|r|}
\hline & bentuk interaksi & $\begin{array}{r}\text { proses penetapan } \\
\text { UMK }\end{array}$ \\
\hline bentuk interaksi & 1 & \\
\hline $\begin{array}{c}\text { prosespenetapan } \\
\text { UMK }\end{array}$ & 0,694091587 & \\
\hline
\end{tabular}

Correlation antara bentuk interaksi dan proses penetapan UMK mendapat hasil angka 0,694091587 yang menjelaskan bahwa hubungan correlation pada proses penetapan UMK di kabupaten Jember memiliki hubungan yang kaut. Jadi interaksi yang berlangsung pada proses penetapan UMK mempunyai dampak yang baik sehingga dapat berjalan dengan baik pada proses penetapan UMK. 
Jurnal Politico Vol. 2 September 2018

Halaman 206-218. ISSN: p; 1829-6696, e:2549-4716

Web jurnal online; jurnal.unmuhjember.ac.id

Emy Kholifah, R., Nor Eviatul Sadiah

PENGARUH INTERAKSI PEMERINTAH, BURUH DAN PELAKU USAHA TERHADAP

PENETAPAN UPAH MINIMUM KABUPATEN

(STUDY KASUS DI KABUPATEN JEMBER)

\section{KESIMPULAN DAN SARAN}

\section{Kesimpulan}

Berdasarkan penelitian diambil kesimpulan bahwa interaksi antara pekerja, pelaku usaha dan pemerintah pada proses penetapan UMK sangat berpengaruh terhadap penetapan UMK di Kabupaten Jember. Interaksi yang terjadi pada proses penetapan UMK dapat menekan terjadinya perselisihan - perselisihan yang memicu terhambatnya penetapan UMK. Dari hal tersebut didapat penjelasan sebagai berikut :

1. Perwakilan pemerintah, pekerja dan pelaku usaha ikut serta setiap tahapan dalam proses penetapan UMK di Kabupaten Jember yang dilakukan setiap tahunya.

2. Adanya kerjasama yang baik dari pemerintah, pelaku usaha dan pekerja yang mendorong tercapainya suatu keputusan tentang jumlah UMK yang akan ditetapkan di Kabupaten Jember. Sehingga jumlah UMK yang sudah disepakati dapat diterima oleh pengusaha dan pekerja.

3. Setiap pihak yang telibat dalam penetapan UMK memiliki hak dan wewenang yang sama.

4. Setiap masalah atau perselisihan yang timbul pemerintah selaku penengah mampu memberikan wadah dan jalan keluar dari setiap permasalahan yang timbul antara pekerja dan pelaku usaha.

5. Setiap keingan dari pekerja maupun pengusaha dapat disampaikan langsung kepada pemerintah. Jika keinginan mereka menyalahi aturan maka pemerintah selaku penengah akan menolaknya.

6. DPRD tidak terlibat ataupun ikut dalam proses penetapan UMK karena proses penetapan UMK hanya dilakukan oleh perwakilan pekerja, pelaku usaha dan pemerintah yang tergabung dalam lebaga kerjasama tripartit.

7. Lembaga kerjasama tripartit sudah melakukan tahapan proses penetapan UMK seperti melakukan survey pasar, menentukan nilai KHL sesuai dengan aturan - aturan yang berlaku. 
Jurnal Politico Vol. 2 September 2018

Halaman 206-218. ISSN: p; 1829-6696, e:2549-4716

Web jurnal online; jurnal.unmuhjember.ac.id

Emy Kholifah, R., Nor Eviatul Sadiah

PENGARUH INTERAKSI PEMERINTAH, BURUH DAN PELAKU USAHA TERHADAP

PENETAPAN UPAH MINIMUM KABUPATEN

(STUDY KASUS DI KABUPATEN JEMBER)

8. Adanya pengaruh interkasi antara pemerintah, pekerja dan pelaku usaha terhadap penetapan upah minimum kabupaten dan corerelasi antara interaksi dan proses penetapan upah minimum kabupaten memiliki hubungan yang kuat.

\section{Saran}

Saran yang dapat diberikan dalam penelitian tentang pengaruh interaksi pemerintah, buruh dan pelaku usaha terhadap penetapan upah minimum kabupaten adalah sebagai berikut :

1. Perlu di tingkatkan lagi kerjasama antara pekerja, pelaku usaha dan pemerintah agar tidak ada lagi masalah atau konflik yang timbul pada proses penetapan UMK.

2. Perlu adanya peraturan agar semua pertokoan dan usaha - usaha yang berkembang di Kabupaten Jember dapat memberikan gaji UMK untuk pekerjanya. Agar tidak hanya perusahaan yang besar saja yang menggaji karyawannya sesuai UMK yang ditetapkan. Hal ini akan mendorong kesejahteraan bagi karyawan atau pekerja. 
Jurnal Politico Vol. 2 September 2018

Halaman 206-218. ISSN: p; 1829-6696, e:2549-4716

Web jurnal online; jurnal.unmuhjember.ac.id

Emy Kholifah, R., Nor Eviatul Sadiah

PENGARUH INTERAKSI PEMERINTAH, BURUH DAN PELAKU USAHA TERHADAP

PENETAPAN UPAH MINIMUM KABUPATEN

(STUDY KASUS DI KABUPATEN JEMBER)

\section{DAFTAR PUSTAKA}

Diknasker. 2014. Petunjuk pelaksanaan Upah Minimum Kabupaten Jember.

Dinas Ketenagakerjaan

Febrianica Danny Nur. 2015. Analisis Dampak Kebijakan Upah Minimum

Terhadap Kemiskinan Di Indonesia. Program Strata 1 Universitas

Brawijaya, Malang

Suseno Franz Magnis. 2001. Pemikiran Karl Marx Dari Sosialisme Utopis ke

Peselisihan Revisionisme, PT Gramedia Pustaka Utama, Jakarta

Soekanto Soerjono. 2012. Sosiologi Suatu Pengantar, PT Raja Grafindo Persada, Jakarta

Soemardjan Selo dan Soermardi Soelaeman. 1964. Setangkai Bunga Sosiologi,

Yayasan Badan Penerbit Fakultas Ekonomi Universitas Indonesia, Jakarta

* Refernsi Non Buku (Online)

Pusdiklatkemnaker.com

https://id.m.wkipedia.org

www.eurekapendidikan.com 